\title{
Genetic structure and relationships among steelhead trout (Oncorhynchus mykiss) populations in British Columbia
}

\author{
DANIEL D. HEATH* ${ }^{*}$, SUSAN POLLARD $\ddagger$ \& CHRISTOPHE HERBINGER \\ $\uparrow$ College of Science and Management, University of Northern British Columbia, 3333 University Way, Prince \\ George, British Columbia, Canada, V2N 4Z9, \$Ministry of Fisheries, Province of British Columbia, 2-780 \\ Blanshard St., Victoria, British Columbia, Canada, V8V 1 X4 and §Marine Gene Probe Laboratory, Department of \\ Biology, Dalhousie University, Halifax, Nova Scotia, Canada, B3H 4J1
}

\begin{abstract}
Steelhead trout, Oncorhynchus mykiss (the anadromous form of rainbow trout), are declining over much of their range around the Pacific rim. We nondestructively collected tissue samples from 494 adult steelhead from eight tributaries and two mainstem river sites within three watersheds in northern British Columbia, Canada. We scored allele size for six highly polymorphic microsatellite DNA loci and provide primer sequences and polymerase chain reaction conditions for five of these loci for the first time. The populations were significantly genetically differentiated $(\theta=0.039 ; 95 \%$ confidence $=0.030-0.053$ ). AMOVA showed that most of the genetic variation was at the individual level $(95.6 \%)$, although significant genetic variation existed at the tributary level $(3.09 \%)$ and watershed level $(1.31 \%)$. The calculated unbiased genetic distances were positively correlated with geographical distance within watersheds $\left(P<0.01 ; r^{2}=0.35\right)$ indicating probable genetic equilibrium. Tributary populations in two of the watersheds were not as genetically divergent as would be expected given their large geographical separation. Cross-headwater transfers of fish within relatively recent history are the most likely explanation of this anomaly. Seven of the eight tributary populations fit a regression line of mean heterozygosity vs. rearing habitat area. The one anomalous population had a much lower heterozygosity than expected based on the linear regression, and may thus be the population of greatest conservation concern.
\end{abstract}

Keywords: conservation, microsatellite DNA, population genetics, rearing habitat, tributary, watershed.

\section{Introduction}

Pacific salmonids represent an interesting challenge for fisheries managers and biologists because they exhibit a wide range of life histories and local adaptation, strong homing behaviour, and a high degree of phenotypic plasticity (Groot \& Margolis, 1991). One species, Oncorhynchus mykiss, exhibits two divergent ecotypes; an anadromous form ('steelhead trout') and a freshwater resident form ('rainbow trout'). Determining patterns and distribution of genetic variation within a species is a key step in understanding the evolutionary legacy of a species as well as in developing management plans that aim to conserve biodiversity (Guyomard, 1993). Until the advent of

*Correspondence and present address: Great Lakes Institute for Environmental Research, University of Windsor, 401 Sunset Avenue, Windsor, Ontario, N9B 3P4, Canada. E-mail: dheath@uwindsor.ca molecular genetic markers, genetic structure was difficult, if not impossible, to determine in natural populations (Avise, 1994). The resolving power and accessibility of molecular genetic markers has increased dramatically over the last 30 years (Avise, 1994; Wright \& Bentzen, 1994). Specifically, allele size variation at microsatellite DNA loci has provided field biologists with a powerful tool for the genetic characterization of natural populations, and has revolutionized the field of conservation genetics (Avise, 1994; Wright \& Bentzen, 1994).

A number of studies have described the genetic structure of $O$. mykiss populations using various molecular genetic markers. Published studies using enzyme variation in steelhead trout showed population structuring at a regional scale; however, finer-scale structure was not consistently or clearly demonstrated (Parkinson, 1984; Reisenbichler et al., 1992). The inconsistencies in the reported population genetic structure 
may reflect either biological differences or the limited resolution of protein electrophoresis. More recently, researchers have used molecular genetic markers of much greater resolution to evaluate the genetic structure of steelhead/rainbow populations. Minisatellite and microsatellite DNA genetic markers have been used with success in identifying population genetic structure in steelhead and rainbow trout (Taylor, 1995; Wenburg et al., 1996; Nielsen et al., 1997; O'Connell et al., 1997; Beacham et al., 1999). This is despite considerable anthropogenic impacts on some of the populations (Nielsen et al., 1997), and one study involving introduced populations (O'Connell et al., 1997). Although the literature dealing with the investigation of genetic structure in $O$. mykiss populations using hypervariable DNA markers is somewhat limited, these markers are clearly useful tools for evaluating population structure in this species.

One specific aspect of fish genetic structure that has received a lot of attention in the ecological and evolutionary literature is the isolation-by-distance model of genetic divergence (Slatkin, 1993). The isolationby-distance model is based upon the expectation of population genetic divergence being driven primarily by reproduction isolation as a function of geographical distance. That is, the further two populations are from one another, the greater their expected genetic distance. A number of examples exist that support the isolationby-distance model in fish (Baer, 1998; Chenoweth et al., 1998; Hansen \& Mensberg, 1998; among others). Adherence to an isolation-by-distance model usually indicates the populations are at, or near, genetic equilibrium (Slatkin, 1993).

The present study was designed to use microsatellite DNA variation to determine the genetic structure of steelhead populations in eight tributaries and three watersheds (Skeena, Nass and Dean) in north-western British Columbia (BC). Intentional inter-watershed transfers of steelhead have been extremely limited throughout BC, particularly on the north coast (BC Ministry of Fisheries, unpublished release records). The sampled steelhead populations are thus expected to reflect original steelhead population structure. Six microsatellite DNA markers developed for O. mykiss were used (one published locus and five loci characterized here for the first time) to address two main questions. (1) Are the sampled populations genetically differentiated? (2) Does the pattern of genetic differentiation conform to an isolation-by-distance model? In addition, we present a potentially useful novel analysis; a regression analysis of mean heterozygosity vs. available juvenile rearing habitat area. The expectation is that, other things being equal, heterozygosity should be positively correlated with juvenile rearing habitat area among the eight tributary populations. This expectation is based on assumed relationships between habitat size and population size, and between population size and genetic diversity. If a relationship between genetic diversity and habitat size is found in natural populations, then a number of management and conservationbased applications may be possible.

\section{Materials and methods}

Steelhead trout are the migratory, anadromous form of rainbow trout. Steelhead trout have a highly variable life history with freshwater residency time ranging from 2 to 5 years, and ocean residency times ranging from 1 to 4 years. Steelhead trout juveniles rear in stream habitat almost exclusively. In north-west British Columbia, steelhead trout return from the ocean to reproduce at characteristic times during the year; summer-run steelhead trout generally return to their natal streams between June and October. Steelhead trout usually show relatively low levels of repeat spawning, and very low levels of straying (see Quinn, 1993).

Adult summer-run steelhead from the Skeena and Nass tributaries were captured pre-spawning from 1992 to 1996, via angling or at a fish fence (Table 1; Fig. 1). Either blood or a fin clip was taken from each fish and preserved in 95\% ethanol. Mainstem Nass River samples were obtained throughout the upstream migration period of summer-run adults from a fishwheel placed in the lower mainstem in 1995, whereas mainstem Dean River steelhead were sampled throughout the upstream migratory period via angling, again in 1995 (Table 1; Fig. 1). The mainstem samples probably include fish from a variety of spawning populations, and thus represent a composite sample. All tributary populations were sampled either on their spawning sites, or just downstream (within $15 \mathrm{~km}$ ). The tributary samples are

Table 1 Number of adult steelhead trout sampled, by location and year of sample

\begin{tabular}{lllllllll}
\hline Drainage & Location & 1992 & 1993 & 1994 & 1995 & 1996 & Total \\
\hline Skeena & Babine & 18 & 20 & - & 50 & - & 88 \\
& Kispiox & - & - & 20 & - & 43 & 63 \\
& Morice & 30 & 20 & - & 17 & 8 & 75 \\
& Sstut & - & 18 & - & 52 & - & 70 \\
& Zymoetz & - & - & 21 & 25 & 5 & 51 \\
\multirow{6}{*}{ Nass } & Mainstem & - & - & - & 37 & - & 37 \\
& Cranberry & - & - & - & - & 19 & 19 \\
& Damdochax & - & - & - & 27 & - & 27 \\
& Kwinageese & - & - & - & - & 11 & 11 \\
\multirow{6}{*}{ Dean } & Mainstem & - & - & - & 53 & - & 53 \\
\hline
\end{tabular}




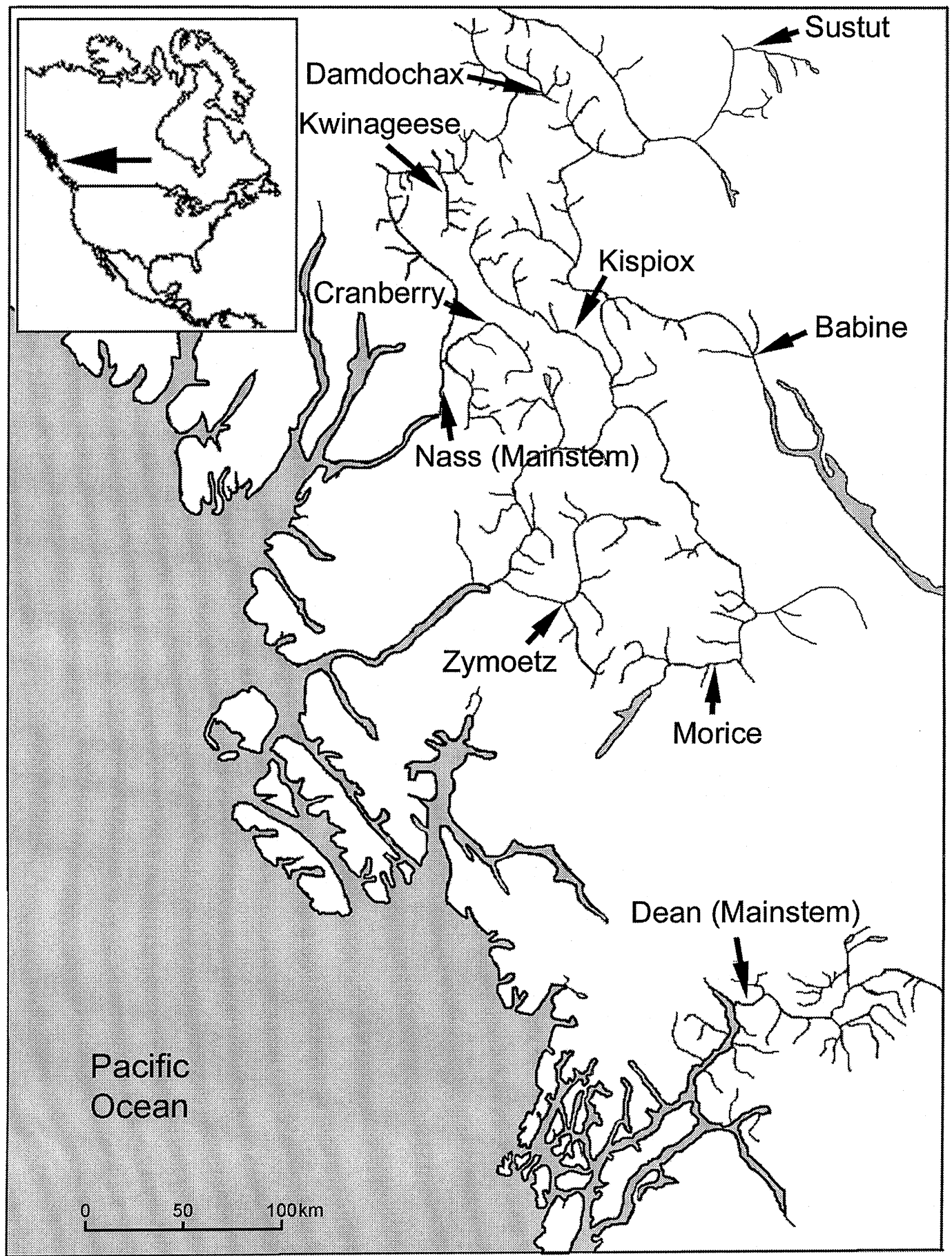

Fig. 1 Map of north-western British Columbia showing the sample sites in the three watersheds (Nass, Skeena, and Dean). The inset shows the study area within North America. All sampling sites are identified by the tributary or watershed name.

thus composed of fish from a single spawning population (D. Atagi, personal communication; Ministry of the Environment, Lands, and Parks; Fisheries Branch, Smithers BC, Canada). The tributary population samples were taken over a range of years in order to maximize sample size (Table 1), but were taken in the same area each year. We sampled only adults, to reduce the chance of sampling related or family groups and to avoid sampling juvenile resident rainbow trout (see Beacham et al., 1999).

(c) The Genetics Society of Great Britain, Heredity, 86, 618-627. 


\section{Genetic analyses}

The Marine Gene Probe Laboratory, Dalhousie University, Halifax, N.S., Canada conducted all laboratory analyses. Variation at six dinucleotide microsatellite loci developed specifically for $O$. mykiss by the Marine Gene Probe Laboratory was evaluated for the 494 steelhead captured. The microsatellite loci included one published marker, Omy77 (Morris et al., 1996), four unpublished markers; Omy2, Omy27, Omy38, Omy105, previously used in other studies (see McConnell et al., 1997) and one new marker Omy111. Primer sequences, repeat motifs and annealing temperatures are provided in Table 2. General polymerase chain reaction (PCR) conditions are as in McConnell et al. (1995). Microsatellite DNA markers were developed following the protocol of Brooker et al. (1994).

\section{Statistical analysis}

Since large sample sizes minimize biases in estimating genetic distances, particularly for microsatellite loci with large numbers of alleles (Ruzzante, 1998), we wished to pool data within populations to maximize our sample sizes. However, allelic frequencies can vary significantly among sampling years depending on population size and sampling procedure (Waples et al., 1990; Beacham et al., 1999). We thus tested for genetic differentiation among the five sampling years (Table 1) within populations, using an exact test for allele frequency distribution differences (1000 dememorization steps; 10 batches; 2000 permutations/batch; Raymond \& Rousset, 1995). Unless otherwise stated, all genetic analyses were performed using Tools for Population Genetic Analyses (TFPGA) software by Mark Miller (Department of Biological Sciences; Northern Arizona University, Flagstaff AZ 86011-5640).

We tested for Hardy-Weinberg equilibrium at each locus for all populations using data pooled across sampling years. An exact test for Hardy-Weinberg equilibrium (i.e. no allele class pooling) was employed; the Monte Carlo method included a total of 20000 permutations (TFPGA). The resulting estimates of the probability of departure from Hardy-Weinberg equilibrium were tested for significance using a sequential Bonferroni correction (Rice, 1989) to account for multiple simultaneous tests.

Among-individual (within tributaries), among-tributary (within watersheds), and among-watershed variance components were calculated using AMOVA (Excoffier et al., 1992). Significance of the variance components was estimated using the nonparametric permutation approach described in Excoffier et al. (1992). Genetic differentiation among populations was quantified by calculating $\theta$ (Weir \& Cockerham, 1984), and the $95 \%$ confidence intervals were estimated using bootstrap analysis over loci. $\theta$ is a common unbiased $F_{\mathrm{ST}}$ estimator that assumes no specific mutation model. We calculated Nei's (1978) unbiased genetic distance for all pairs of populations, and tested for genetic differentiation between the pairs using an exact test for allele frequency distribution differences (1000 dememorization steps; 10 batches; 2000 permutations/batch; Raymond \& Rousset, 1995). Significance was adjusted for multiple simultaneous comparisons using the sequential Bonferroni correction (Rice, 1989).

Table 2 Summary of microsatellite locus characteristics of steelhead trout. Allele size range and numbers are based on entire data $\operatorname{set}(N=494)$

\begin{tabular}{|c|c|c|c|c|c|}
\hline Locus & $\begin{array}{l}\text { Repeat } \\
\text { motif }\end{array}$ & $\begin{array}{l}\text { Primer sequences } \\
\left(5^{\prime} \text { to } 3^{\prime} \text { orientation }\right)\end{array}$ & $\begin{array}{l}\text { Allele size } \\
\text { range (bp) }\end{array}$ & $\begin{array}{l}\text { Number } \\
\text { of alleles }\end{array}$ & $\begin{array}{l}\text { Annealing } \\
\text { temperature }\end{array}$ \\
\hline Omy 2 & $(\mathrm{GT})_{n}$ & $\begin{array}{l}\text { CTGCTGATTCTCCCTGTTGC } \\
\text { TCTATACTTCCAGACAATGGC } \dagger\end{array}$ & $84-172$ & 34 & 57 \\
\hline Omy27 & $(\mathrm{GT})_{n}$ & $\begin{array}{l}\text { TTTATGTCATGTCAGCCAGTG } \\
\text { TTTATGGCTGGCAACTAATGT } \dagger\end{array}$ & $98-120$ & 7 & 57 \\
\hline Omy38 & $(\mathrm{GT})_{n}$ & $\begin{array}{l}\text { TGGTTGTTGCCATTTGTCTC } \\
\text { GCCTGTATTGTCTGAGAAGG } \dagger\end{array}$ & $92-138$ & 23 & 53 \\
\hline Omy77ł & $(\mathrm{GA})_{n}$ & $\begin{array}{l}\text { CGTTCTCTACTGAGTCAT } \\
\text { CCAAGAATTTTCTGATCCGGG } \dagger\end{array}$ & $98-134$ & 13 & 52 \\
\hline Omyl05 & $(\mathrm{GT})_{n}$ & $\begin{array}{l}\text { TGATCATTATATTACTTGACTG } \\
\text { AGAAGCTTTCTGATAGTCTG } \dagger\end{array}$ & 109-271 & 40 & 51 \\
\hline Omy111 & $(\mathrm{GT})_{n}$ & $\begin{array}{l}\text { ATGATTTGCAAACAGTGCCTG } \\
\text { GTAGCAAATTCCTGCCCTGC }{ }^{\dagger}\end{array}$ & 99-177 & 36 & 57 \\
\hline
\end{tabular}

$\dagger$ Labelled primer.

$\$$ Omy77 is described in Morris et al. (1996).

(c) The Genetics Society of Great Britain, Heredity, 86, 618-627. 
We graphically represented the pattern of genetic differentiation using UPGMA cluster analysis based on Wright's (1978) modification of Roger's genetic distance for the eight tributaries (five in the Skeena and three in the Nass watersheds) and the Dean mainstem sample as a presumed outgroup. We bootstrapped with replacement among loci with 1000 permutations to get an estimate of node consistency (TFPGA). Finally, we checked for tied trees among all bootstrap topologies to determine the reliability of the bootstrap data (Backeljau et al., 1996) since tied trees may lead to misleading estimates of node consistency.

To test for an isolation-by-distance model of genetic divergence for steelhead trout we regressed genetic distance on geographical distance for pairs of samples. We used Nei's (1978) unbiased genetic distance as well as Wright's (1978) modification of Roger's genetic distance vs. geographical distance measured along the shortest river and/or ocean pathway (measured on 1:250 000 scale maps). We analysed the data using all pairwise comparisons, excluding the Nass mainstem sample $(n=36)$, we then analysed a subset of the data that included only sample comparisons within watersheds $(n=13 ; 10$ from within the Skeena, three from within the Nass). We also used a Mantel test to verify the results of the regression analysis on the full dataset.

Although no reliable estimates of population size exist for the sampled tributaries, estimates of available juvenile rearing habitat have been calculated (unpublished data, D. Atagi; Ministry of the Environment, Lands and Parks, Fisheries Branch, Smithers, BC, Canada). In brief, stream area was estimated using stream length and mean stream width; stream length was estimated from 1:50 000 maps, and stream width was estimated using mean annual discharge rates. The fraction of the stream area that was usable for juvenile steelhead rearing was estimated from existing data on steelhead juvenile rearing habitat characteristics, aerial photography, and topographical map estimates of stream gradient. The accuracy of the estimation was cross-checked by comparison with data from streams that had been directly mapped for juvenile steelhead presence. Juvenile rearing habitat was estimated for the summer low-flow period to ensure conservative estimates. To test for a relationship between rearing habitat (and thus presumably carrying capacity) and heterozygosity, we plotted mean heterozygosity ( $\pm 1 \mathrm{SE}$ ) against rearing habitat area for each of the eight tributary populations.

\section{Results}

All six microsatellite loci were moderately to highly polymorphic in all of the populations, with the total number of alleles observed ranging from seven to 40 (Table 2). There was limited variation among samples in mean heterozygosity (across all loci), which was generally high and ranged from 0.75 for the Damdochax sample to 0.85 for the Morice sample (Table 3).

No significant differences in allele frequency distribution among sample years (within populations) were found $(P>0.10)$; thus we pooled data within populations for all subsequent analyses. In general, populations did not significantly depart from Hardy-Weinberg expectations (58 out of 60 comparisons) after sequential Bonferroni correction. The exceptions were locus Omyl11 in the Babine sample $(P<0.001)$ and locus Omy105 in the Kispiox sample $(P<0.001)$. These discrepancies resulted from an excess of homozygotes and could be due to the presence of null alleles or to sampling error associated with possible subdivision of the tributary populations.

All measures of genetic differentiation among tributary populations and watersheds were highly significant. Unbiased genetic distance (Nei, 1978) among pairs of sampling locations varied considerably in magnitude, but most were highly significant, even after sequential Bonferonni correction (Table 3). The variance components, as calculated by AMOVA, were: among watersheds $0.034(P<0.05)$; among tributaries $0.078(P<0.001)$; and among individuals $2.43(P<0.001)$. The variance was partitioned as: among watersheds $1.31 \%$; among tributaries 3.09\%; and among individuals $95.6 \%$. The mean $\theta$ for all tributary populations was 0.0392 , with a bootstrapped $95 \%$ confidence interval of $0.030-0.053$.

The UPGMA cluster analysis of the eight tributaries from the Nass and Skeena watersheds (plus the Dean mainstem) showed no particular clustering at the watershed level, with the exception of the Dean mainstem sample, which was clearly divergent (Fig. 2). The bootstrap values were low for most nodes; however, one stands out as being relatively well supported: the Morice, Damdochax, Babine and Kispiox Rivers vs. the rest of the samples (Fig. 2). There were no tied trees found in the cluster analysis.

We found a weak positive correlation between unbiased genetic distance (Nei, 1978) and geographical distance (Fig. 3, all points, solid line; $P<0.05$, $r^{2}=0.10$ ); however, when comparisons between watersheds were removed, the relationship was strengthened (Fig. 3, filled circles, dashed line; $P<0.01 ; r^{2}=0.35$ ). The use of other genetic distance measures (e.g. Wright's (1978) modification of Roger's genetic distance) produced marginally significant relationships with decreased explained variance. Inspection of the data points generated by comparing the two upstream Nass tributaries (Kwinageese and Damdochax) vs. the upstream Skeena tributaries indicates that these comparisons fall well 


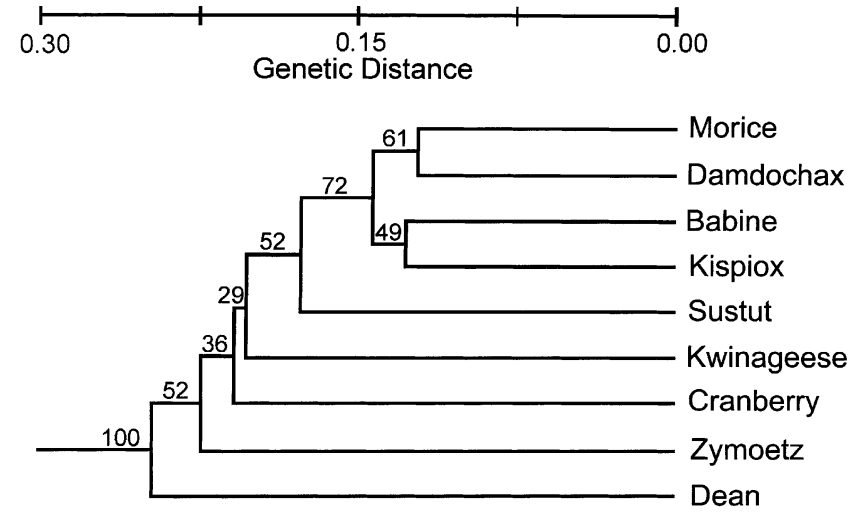

Fig. 2 UPGMA cluster diagram based on Wright's modification of Roger's genetic distance for eight tributary populations (from the Skeena and Nass watersheds) and the Dean mainstem (presumed outgroup) steelhead trout samples. Genetic distance was calculated using data from six microsatellite loci. The bootstrap values are based on 1000 permutations.

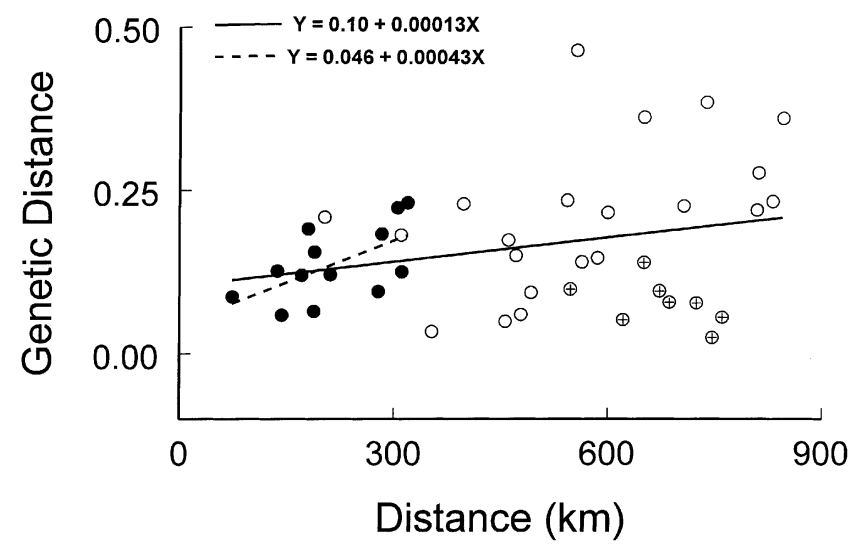

Fig. 3 Regression of unbiased genetic distance (Nei, 1978) on geographical distance for all pairwise comparisons of sampled steelhead trout populations (solid line and all circles). The dashed line (and filled circles) represents the same regression but includes only the within-watershed comparisons. The circles with the cross in the centre are the upstream Nass vs. upstream Skeena tributary comparisons. Regression equations are shown.

below the overall relationship (circles with cross; Fig. 3). Indeed, the relationship between genetic distance and geographical distance was considerably strengthened when those comparisons were excluded $(P<0.001$; $\left.r^{2}=0.46\right)$. The full dataset yielded a marginally significant relationship between unbiased genetic distance and geographical distance when analysed with the Mantel test $(P=0.059)$.

No significant linear relationship was found between mean heterozygosity and juvenile rearing habitat for the

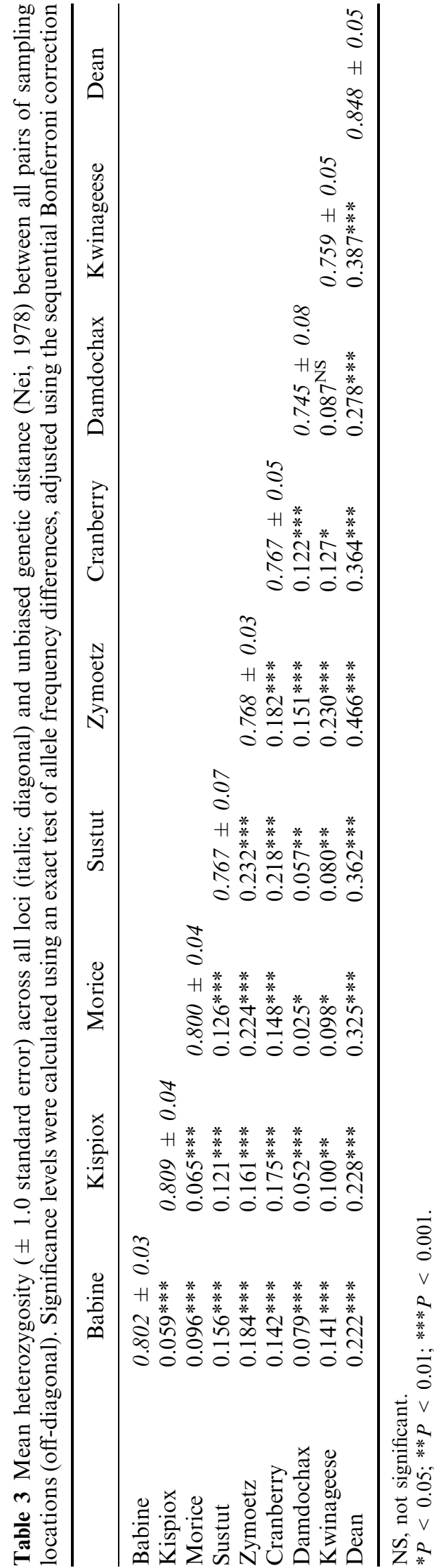

(c) The Genetics Society of Great Britain, Heredity, 86, 618-627. 


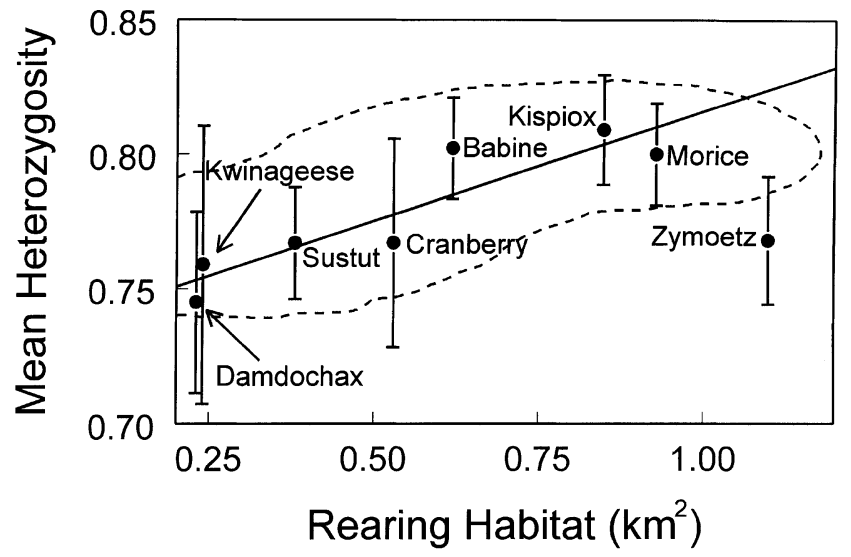

Fig. 4 Scatterplot of mean heterozygosity $( \pm 1.0$ standard error) and juvenile rearing habitat area for populations of steelhead trout from the three Nass tributaries and the five Skeena tributaries. The solid line is the fitted linear regression based on all but the Zymoetz River population $\left(r^{2}=0.83\right.$; $P<0.001)$. The dashed line represents the $95 \%$ confidence kernel for the regression.

eight tributary populations $(P>0.15)$. However, one tributary population (Zymoetz) was classified as a statistical outlier (Dixon, 1950). When this population was excluded, a highly significant positive slope linear regression line between mean heterozygosity vs. juvenile rearing habitat was observed (Fig. 4; $P<0.001$; $r^{2}=0.83$ ). The dashed line represents the $95 \%$ confidence kernel (Wilkinson, 1990) for the regression of the seven tributaries (excluding Zymoetz River).

\section{Discussion}

In the absence of other factors, we would expect that steelhead trout populations in northern BC would be highly genetically differentiated due to accurate homing behaviour (low gene flow among rivers; Quinn, 1993) and local adaptation. It is thus perhaps not surprising that we found high levels of genetic differentiation among populations in this study, especially since no human-mediated transfers of fish among the river populations studied here are known to have occurred (personal communication R. S. Hooton, Ministry of the Environment, Lands, and Parks, Fisheries Branch, Smithers BC). Our sampling of adult fish minimized the possibility that the genetic differentiation was an artifact due to sampling genetically related juvenile fish, or transient selection factors on juvenile stocks (Beacham et al., 1999).

Beacham et al. (1999) used eight microsatellite loci to examine population genetic structure in 22 populations of steelhead in southern BC and Washington. They found evidence for strong population divergence, but even greater divergence was observed among regions. The level of genetic differentiation presented here $(\theta=0.0392)$ is similar to those reported in other studies of O. mykiss. Nielsen et al. (1997) analysed 541 adult and juvenile rainbow and steelhead trout from 29 sites in Southern California using three microsatellite loci. Their estimate of mean $F_{\mathrm{ST}}(0.07)$ was almost twice our estimate; however, this probably reflects the high degree of population isolation among some of their samples, as well as their inclusion of both resident (rainbow) and anadromous (steelhead) trout in their analysis. Studies at larger geographical scales report, as expected, similar or higher estimates of genetic differentiation. Corrected $F_{\mathrm{ST}}$ values calculated for northern $\mathrm{BC}$ and Alaska steelhead and rainbow trout populations based on two minisatellite loci were 0.058 and 0.039 (Taylor, 1995). In some systems, the practice of supplementing or stocking trout and salmon populations using fish or gametes of different river origin is common (Waples, 1994). This practice can lead to artificial gene flow that is expected to erode genetic differentiation (Waples, 1994). Our data are therefore a good baseline for populations without known historical supplementation or stocking, and thus may have value for comparisons to steelhead populations in less pristine systems.

The nature of the genetic differentiation among our steelhead populations was clarified when genetic distance was plotted against geographical distance (see Fig. 3). Our correlation between unbiased genetic distance and geographical distance suggests that the mechanism of population differentiation in undisturbed steelhead trout populations is probably isolation by distance (Slatkin, 1993), at least within watersheds. Since our data support the isolation-by-distance model, the steelhead populations are probably at, or near, genetic equilibrium (Slatkin, 1993; Chenoweth et al., 1998). However, closer inspection of the genetic/ geographical distance scatterplot shows that the comparisons of upstream Nass watershed tributaries with those of the Skeena watershed produced lower than expected genetic distances, given their large geographical separation (circles with cross; Fig. 3). Perhaps the most likely explanation of this pattern is fairly recent movement of adults and/or juveniles (i.e. gene flow) across the Skeena and Nass headwaters - which are geographically close (Fig. 1). This is supported by the strengthening of the relationship with the exclusion of the between-watershed comparisons (filled circles; Fig. 3). The possibility of cross-headwater gene flow is further supported by the UPGMA cluster diagram of the genetic distances among tributaries; specifically, the clustering of an upstream Nass tributary (Damdochax River) with Skeena tributaries (Fig. 2). The evidence from the cluster analysis is made somewhat ambiguous by the presence of a 
southern Skeena tributary (Morice) within the cluster. Regardless of the details of the structure of the cluster diagram, it is clear that the Nass and Skeena tributaries do not cluster separately (Fig. 2). Since there have been no intentional cross-watershed steelhead introductions, any gene flow between the watersheds would have to have been due to natural processes. Phylogeographic studies of salmonid fish species in BC have shown largescale patterns of relatedness, presumably due to postglacial recolonization from multiple refugia (McPhail \& Lindsey, 1986; Taylor, 1995; Teel et al., 2000; among others). Although these large-scale effects may have contributed to our observed pattern of genetic relatedness in the upper Nass and Skeena steelhead populations, it probably is not a major factor due to the very high mutation rate characteristic of microsatellite DNA loci.

Cross-watershed gene flow would also explain our unexpected AMOvA results: the variance among watersheds was less than half of that among tributaries $(1.31 \%$ and $3.09 \%$, respectively). Although the vast majority of genetic variation at these microsatellite loci exists at the individual level $(95.6 \%)$, it is surprising that there is more variance among tributaries (within watersheds) than among watersheds. This is in contrast to work reported by Beacham et al. (1999), where they found $4.4 \%$ of the genetic variance among regions, and $3.1 \%$ of the variance among populations (within regions). Reisenbichler et al. (1992) found a similar pattern to that of Beacham et al. (1999), with amongdrainage variance being almost four times higher than among-population variance $(0.86 \%$ and $0.22 \%$, respectively). Even low levels of gene flow between upstream Nass and Skeena populations in our study would serve to erode among-watershed variance, but would not greatly affect among-tributary variance. Such gene flow would thus explain the unusual partitioning of the genetic variance. It should be noted, however, that the Nass tributaries were represented by relatively small sample sizes (see Table 1) due to the logistic difficulties of accessing these remote areas and the small sizes of these populations. Although we feel that our results are robust, the possibility remains that our results may be affected by these less than ideal sample sizes.

A positive relationship between population size and genetic diversity is theoretically expected (Avise, 1994; Amos \& Harwood, 1998; Bouzat et al., 1998), and a few examples have been reported for natural populations (Bouzat et al., 1998; Fischer \& Matthies, 1998). More is known of the impact of changes in population size on heterozygosity: generally a decrease in population size is accompanied by a decrease in heterozygosity (Waples, 1989). In many cases, however, it is logistically impossible to assess population size, particularly in fish and other aquatic species. In such cases it may be possible to measure range or habitat area as an indirect estimator of population size. In this study we had no estimates of population size for the tributaries (due to their remote locations), but we were able to estimate juvenile rearing habitat area. Thus the mechanism behind our positive relationship between rearing habitat and mean heterozygosity (Fig. 4) may be that large rivers support large populations, which are characterized by high genetic diversity. Clearly such a relationship would only be expected in systems that are relatively pristine and near the habitat's carrying capacity. Our data, for seven of the tributary populations, show such a positive relationship (Fig. 4). One tributary population, however, was found to be a statistical outlier (Zymoetz River). The Zymoetz River has the largest rearing habitat area of any of the sampled populations; however, the mean heterozygosity is considerably lower than predicted based on the regression (Fig. 4). There are a number of possible explanations of this pattern, including statistical artifacts and/or population sampling error/ bias. One interesting possibility is that the Zymoetz River population is below the river's juvenile habitat carrying capacity. That is, human and/or natural disturbance in the Zymoetz watershed may be driving the actual population size below that expected based on measured available habitat; this would account for the low heterozygosity of the Zymoetz population (Fig. 4). It is thought that the marine stage of the anadromous salmonid life cycle is where the largest survival limitations generally occur (see Welch et al., 2000). However, our analysis is independent of where the mortality occurs, it only responds to populations that are below carrying capacity, for any reason. Clearly our data cannot determine the generality of the heterozygosity habitat area correlation, nor explain the outlying population (Zymoetz); however, future studies, and re-analysis of existing data, could address such questions.

We are not aware of any other published regression analysis of habitat area vs. microsatellite DNA heterozygosity. Despite the fact that the mechanism behind such a relationship may not be clear, it will still have considerable value for identifying populations that are anomalous with respect to conservation genetic status, and may thus provide an objective method for setting conservation or future research priorities.

\section{Acknowledgements}

We would like to gratefully acknowledge the assistance of the Skeena \& Cariboo Region Ministry of Environment, Lands and Parks (MELP-BC) staff and the Nisga'a Fisheries Program in the collection of the samples. Our thanks also go to Dana Atagi (MELP, Smithers BC) for his support and suggestions. Funding 
for part of the fieldwork and the laboratory analysis was provided by the BC Habitat Conservation Trust Fund. Additional funding was provided through an NSERC research grant to DDH. Doug Cook (Marine Gene Probe Laboratory) provided invaluable help with all the genetic analyses.

\section{References}

AMOS, W. AND HARwOOD, J. 1998. Factors affecting levels of genetic diversity in natural populations. Phil. Trans. R. Soc. B, 353, 177-186.

AVISE, J. C. 1994. Molecular Markers, Natural History and Evolution. Chapman \& Hall, New York.

BACKELJAU, T., DE BRUYN, L., DE WOLF, H., JORDAENS, K. ET AL. 1996. Multiple UPGMA and neighbor-joining trees and the performance of some computer packages. Mol. Biol. Evol., 13, 309-313.

BAER, C. F. 1998. Species-wide population structure in a southeastern U.S. freshwater fish, Heterandria formosa: gene flow and biogeography. Evolution, 52, 183-193.

BEACHAM, T. D., POLlARD, S. AND KHAI, D. L. 1999. Population structure and stock identification of steelhead in southern British Columbia, Washington, and the Columbia River based on microsatellite DNA variation. Trans. Am. Fish. Soc., 128, 1068-1084.

BOUZAT, J. L., CHENG, H. H., LEWIN, H. A., WESTMEIER, R. L. ET $A L$. 1998. Genetic evaluation of a demographic bottleneck in the greater prairie chicken. Cons. Biol., 12, 836-843.

BROOKER, A. L., COOK, D., BENTZEN, P., WRIGHT, J. M. ET AL. 1994. Organization of microsatellites differs between mammals and cold-water teleost fishes. Can. J. Fish. Aquat. Sci., 51, 1959-1966.

CHENOWETH, S. F., HUGHES, R. M., KEENAN, C. P. AND LAVERY, S. 1998. Concordance between dispersal and mitochondrial gene flow: isolation by distance in a tropical teleost, Lates calcarifer (Australian barramundi). Heredity, 80, 187-197.

DIXON, w. J. 1950. Analysis of extreme values. Ann. Math. Stat., 21, 488-506.

EXCOFFIER, L., SMOUSE, P. AND QUATTRO, J. 1992. Analysis of molecular variance inferred from metric distances among DNA haplotypes: applications to human mitochondrial DNA restriction data. Genetics, 131, 479-491.

FISCHER, M. AND MATTHIES, D. 1998. RAPD variation in relation to population size and plant fitness in the rare Gentianella germanica (Gentianaceae). Am. J. Bot., 85, 811-819.

GRoOT, C. AND MARgolis, L. 1991. Pacific Salmon Life Histories. University of British Columbia Press, Vancouver. GUYOMARD, R. 1993. Methods to describe fish stocks. In: Cloud, J. G. and Thorgaard, G. H. (eds) Genetic Conservation of Salmonid Fishes, pp. 1-22. Proceedings of a NATO Advanced Study Institute, Plenum, New York.

HANSEN, M. M. AND MENSBERG, K.-L. D. 1998. Genetic differentiation and relationship between genetic and geographical distance in Danish sea trout (Salmo trutta L.) populations. Heredity, 81, 493-504.
MCCONNELL, S. K., O'REILlY, P., HAMILTON, L., WRIGHT, J. M. ET AL. 1995. Polymorphic microsatellite loci from Atlantic salmon (Salmo salar): genetic differentiation of North American and European populations. Can. J. Fish. Aquat. Sci., 52, 1863-1872.

MCCONNELL, S. K. J., RUZZANTE, D. E., O'REILLY, P. T., HAMILTON, L. ET AL. 1997. Microsatellite loci reveal highly significant genetic differentiation among Atlantic salmon (Salmo salar L.) stocks from the east coast of Canada. Mol. Ecol., 6, 1075-1089.

MCPHAIL, J. D. AND LINDSEY, C. C. 1986. Zoogeography of the freshwater fishes of Cascadia (the Columbia systems and rivers north to the Stikine). In: Hocutt, C. H. and Wiley, E. O. (eds) Zoogeography of North American Freshwater Fishes, pp. 615-637. Wiley, New York.

MORRIS, D. B., RICHARD, K. R. AND WRIGHT, J. M. 1996. Microsatellites from rainbow trout (Oncorhynchus mykiss) and their use for genetic study of salmonids. Can. J. Fish. Aquat. Sci., 53, 120-126.

NEI, M. 1978. Estimation of average heterozygosity and genetic distance from a small number of individuals. Genetics, $\mathbf{8 9}$, 583-590.

NIELSEN, J. L., CARPANZANO, C., FOUNTAIN, M. C. AND GAN, C. A. 1997. Mitochondrial DNA and nuclear microsatellite diversity in hatchery and wild Oncorhynchus mykiss from freshwater habitats in southern California. Trans. Am. Fish. Soc., 126, 397-417.

O'CONNELL, M., DANZMANN, R. G., CORNUET, J.-M., WRIGHT, J. M. ET AL. 1997. Differentiation of rainbow trout (Oncorhynchus mykiss) populations in Lake Ontario and the evaluation of the stepwise mutation and infinite allele mutation models using microsatellite variability. Can. J. Fish. Aquat. Sci., 54, 1391-1399.

PARKINSON, E. 1984. Genetic variation in populations of steelhead trout (Salmo gairdneri) in British Columbia. Can. J. Fish. Aquat. Sci., 41, 1412-1420.

QUINN, T. P. 1993. A review of homing and straying of wild and hatchery-produced salmon. Fish. Res., 18, 29-44.

RAYMOND, M. AND ROUSSET, F. 1995. An exact test for population differentiation. Evolution, 49, 1280-1283.

REISENBICHLER, R. R., MCINTYRE, J. D., SOLAZZI, M. F. AND LANDING, S. W. 1992. Genetic variation in steelhead of Oregon and northern California. Trans. Am. Fish. Soc., 121, 158-169.

RICE, W. R. 1989. Analyzing tables of statistical tests. Evolution, 43, 223-225.

RUZZANTE, D. E. 1998. A comparison of several measures of genetic distance and population structure with microsatellite data: bias and sampling variance. Can. J. Fish. Aquat. Sci., 55, $1-14$.

SLATKIN, M. 1993. Isolation by distance in equilibrium and non-equilibrium populations. Evolution, 47, 264-279.

TAYLOR, E. B. 1995. Genetic variation at minisatellite DNA loci among north Pacific populations of Steelhead and Rainbow trout (Oncorhynchus mykiss). J. Hered., 86, 354-363.

TEEL, D., MILNER, G., WINANS, G. AND GRANT, W. S. 2000. Genetic population structure and origin of life history types in Chinook salmon in British Columbia, Canada. Trans. Am. Fish. Soc., 129, 194-209. 
WAPLES, R. S. 1989. A generalized approach for estimating effective population size from temporal changes in allele frequency. Genetics, 121, 379-391.

WAPLES, R. S. 1994. Genetic considerations in recovery efforts for Pacific salmon. Cons. Biol., 8, 884-886.

WAPLES, R. S., WINANS, G. A., UTTER, F. M. AND MAHNKEN, C. 1990. Genetic monitoring of Pacific salmon hatcheries. In: Svrjcek, R. S. (ed.) Genetics in Aquaculture: Proceedings of the Sixteenth U.S-Japan Meeting on Aquaculture, pp. 33-37. NOAA Technical Report NMFS 92.

WEIR, B. S. AND COCKERHAM, C. C. 1984. Estimating $F$-statistics for the analysis of population structure. Evolution, 38, 1358-1370.

WELCH, D. W., WARD, B. R., SMITH, B. D. AND EVESON, J. P. 2000. Temporal and spatial responses of British Columbia steel- head (Oncorhynchus mykiss) populations to ocean climate shifts. Fish. Oceanography, 9, 17-32.

WENBURG, J. K., OLSEN, J. B. AND BENTZEN, P. 1996. Multiplexed systems of microsatellites for genetic analysis in coastal cutthroat trout (Oncorhynchus clarki clarki) and steelhead (Oncorhynchus mykiss). Mol. Mar. Biol. Biotech., 5, 273-283.

WILKINSON, L. 1990. SYSTAT: The system for statistics. SYSTAT Inc., Evanston.

WRIGHT, J. M. AND BENTZEN, P. 1994. Microsatellites: genetic markers for the future. Rev. Fish Biol. Fish., 4, 384-388.

WRIGHT, S. 1978. Evolution and Genetics of Populations: Variability Within and Among Natural Populations. University of Chicago Press, Chicago. 